\title{
Validation of the Aura High Resolution Dynamics Limb Sounder geopotential heights
}

\author{
L. L. Smith ${ }^{1}$ and J. C. Gille ${ }^{1,2}$ \\ ${ }^{1}$ Atmospheric Chemistry Division, National Center for Atmospheric Research, Boulder, Colorado, USA \\ ${ }^{2}$ Center for Limb Atmospheric Sounding, University of Colorado, Boulder, Colorado, USA \\ Correspondence to: L. L. Smith (1smith@ucar.edu)
}

Received: 16 January 2014 - Published in Atmos. Meas. Tech. Discuss.: 5 February 2014

Revised: 27 June 2014 - Accepted: 3 July 2014 - Published: 29 August 2014

\begin{abstract}
The geopotential height $(\mathrm{GPH})$ product created from global observations by the High Resolution Dynamics Limb Sounder (HIRDLS) instrument on NASA's Earth Observing System (EOS) Aura spacecraft is discussed. The accuracy, resolution and precision of the HIRDLS version 7 algorithms are assessed and data screening recommendations are made. Comparisons with GPH from observations, reanalyses and models including European Centre for MediumRange Weather Forecasts Interim Reanalysis (ERA-Interim), and National Centers for Environmental Prediction/National Center for Atmospheric Research (NCEP/NCAR) Reanalysis illustrate the HIRDLS GPHs have a precision ranging from 2 to $30 \mathrm{~m}$ and an accuracy of $\pm 100 \mathrm{~m}$ up to $1 \mathrm{hPa}$. Comparisons indicate HIRDLS GPH may have a slight low bias in the tropics and a slight high bias at high latitudes. Geostrophic winds computed with HIRDLS GPH qualitatively agree with winds from other data sources including ERA-Interim.
\end{abstract}

\section{Introduction}

The High Resolution Dynamics Limb Sounder (HIRDLS) instrument is an infrared limb-scanning radiometer onboard NASA's Aura satellite, launched on 15 July 2004. HIRDLS was designed to obtain high vertical and horizontal resolution observations in the upper troposphere, the stratosphere, and the lower mesosphere, at altitudes of $8-80 \mathrm{~km}$. HIRDLS was proposed to address scientific issues of smaller-scale dynamical and chemical phenomena, particularly near the tropopause.
The HIRDLS instrument measures atmospheric limb emissions in 21 spectral channels between 6.12 and $17.76 \mu \mathrm{m}$ to obtain vertical profiles of pressures, temperatures, and mixing ratios of 10 species as well as other quantities such as cloud top pressures and aerosol extinction at $12.1 \mu \mathrm{m}$.

The HIRDLS geopotential height (GPH) profiles are computed from the temperature profiles. The results discussed here are Level 3 gridded products, created on a $1^{\circ} \times 1^{\circ}$ grid, which facilitates calculation of the geostrophic zonal and meridional winds.

This paper is organized as follows. In Sect. 2, the HIRDLS temperature and tangent height at nominal altitude (THNA) measurements are described, and the GPH calculation is outlined. In Sect. 3, we briefly discuss HIRDLS temperatures and compare HIRDLS GPH to ERA-Interim, since it is well-regarded and appears representative of other data sources, including National Centers for Environmental Prediction/National Center for Atmospheric Research Reanalysis (hereafter called NCEP), Goddard Earth Observing System Model (GEOS) version 5, the NCAR Whole Atmosphere Community Climate Model (WACCM) version 4, and the EOS Aura Microwave Limb Sounder (MLS), which are also noted. In Sect. 4, we compare geostrophic winds computed with HIRDLS GPH to other geostrophic winds including ERA-Interim and GEOS-5. Mesospheric applications are discussed in Sect. 5. Finally, in Sect. 6, we draw some conclusions. 


\section{HIRDLS temperature measurement and GPH calculation descriptions}

\subsection{The HIRDLS measurement system}

HIRDLS utilizes the infrared limb scanning method, in which the radiance emitted by the atmosphere observed at the limb, or horizon, is measured in 21 channels as a function of relative altitude. An algorithm processes the radiances to retrieve temperature, trace constituents and aerosols as a function of pressure, incorporating the hydrostatic relationship, over the range of altitudes for which the signal has not saturated and for which there is a good signal-to-noise ratio. The retrieval process has been described by Khosravi et al. (2009a, b).

Four of HIRDLS channels measure radiance in the $15 \mu \mathrm{m}$ bands of $\mathrm{CO}_{2}$, from which temperature is retrieved as a function of pressure. Channels in the more opaque centers of the bands provide most information on the upper altitudes, while channels in the more transparent band wings allow sounding of lower altitudes, including the desirable upper troposphere/lower stratosphere (UT/LS) region. Additionally, channels with minimal absorption by atmospheric gases can be utilized to observe particulates such as aerosols and clouds.

Unfortunately, during launch the instrument aperture suffered a significant blockage, believed to be due to a piece of plastic film that came loose and settled in the optical train. The most definitive consequence of the blockage is that useful scans can only be obtained at the largest azimuth angle away from the Sun, or a line of sight (LOS) of $47^{\circ}$ on the antiSun side of the orbital plane, looking backward. This limits the longitudinal resolution to the orbital spacing of $24.72^{\circ}$, prevents coverage south of $63^{\circ} \mathrm{S}$ and north of $80^{\circ} \mathrm{N}$, and precludes simultaneous measurements with other A-Train instruments. However, the HIRDLS team has managed to obtain significant useful data, as outlined in Gille et al. (2008) and elsewhere.

For version 7, HIRDLS has released Level 3 data zonal Fourier coefficient data files, created by applying a Kalman filter mapping algorithm similar to that described by Rodgers (2000), Kohri (1981), and Remsberg et al. (1990). In this process each data point is used to update estimates of the zonal mean and coefficients of the sine and cosine coefficients of the first seven zonal waves ( 15 values, equivalent to the mean plus amplitudes and phases of the first seven zonal waves). This is done for each pressure level and zonal band going both forward and backward in time, and the results are combined, thus ensuring smooth time evolution. Values are output at one time of day, 12:00 UT, resulting in daily values of the estimated quantities every $1^{\circ}$ in latitude. This produces an optimal estimate of the state of the atmosphere in this representation. In general the final estimated field will not go through the input points, but will have an rms difference from them, termed the precision, approximately equal to the precision of the single profile observations. The output data include this rms value, as well as the values from each of the diagonal elements of the covariance matrix that give the predicted variance of each of the estimated quantities. The output data also include the number of points that went into producing the estimate for that day. Since the Kalman estimator produces estimates even in the absence of data, a negative number of points indicates the number of days without data since (or until) a day with data, but the largest gap in this analysis is less than a day.

All HIRDLS data discussed here are from version 7, available at the NASA GSFC Earth Sciences (GES) Data and Information Services Center (DISC): http://disc.sci.gsfc.nasa. gov/Aura/data-holdings/HIRDLS. Data discussed here are presented from 29 January 2005 until 17 March 2008, although occasional periods of less than a day are missing when various non-science scans were run for test purposes.

\subsection{ERA-Interim data}

Many of the comparisons of GPHs and winds described here have been done with the European Centre for Medium-Range Weather Forecasts interim re-analyses (ERA-Interim). This is the latest global atmospheric reanalysis product created by ECMWF and provides an estimate of the state of the atmosphere based on assimilating all available observations (approximately $10^{7}$ per day as of 2010) in a state-of-the-art forecast model to estimate the evolving state of the atmosphere (Dee et al., 2011, and references therein). Poli et al. (2010) and references discuss assimilating radio occultation data in ERA-Interim and observe that adding such data improves the standard deviation fit of the ERA-Interim Reanalysis to radiosonde temperature and wind observations. Since geopotential height and temperature are so closely related, we expect that ERA-Interim geopotential heights will have similar improvements.

Because the number of observations falls off above $30 \mathrm{~km}$, and even more so above $40 \mathrm{~km}$, the quality of the data will depend more on model performance at higher altitudes, and thus may not be as accurate as at lower altitudes.

\subsection{HIRDLS temperature measurements}

The HIRDLS retrieval algorithm has been previously described by Khosravi et al. (2009a, b, and references therein). Briefly, the retrieval algorithm is a maximum a posteriori retrieval (Rodgers, 2000) of the radiances determined from channels 2-5 (14.7-16.7 $\mu \mathrm{m})$, following the physics described by Gille and House (1971). Input data are on a uniform altitude scale, while the solution returns the temperature and pressure at these levels, with the altitude and pressure hydrostatically consistent.

HIRDLS uses GEOS-5 assimilated meteorological data to provide LOS gradients as well as the first guess for the retrieval. On each iteration, the LOS gradient is fixed and 


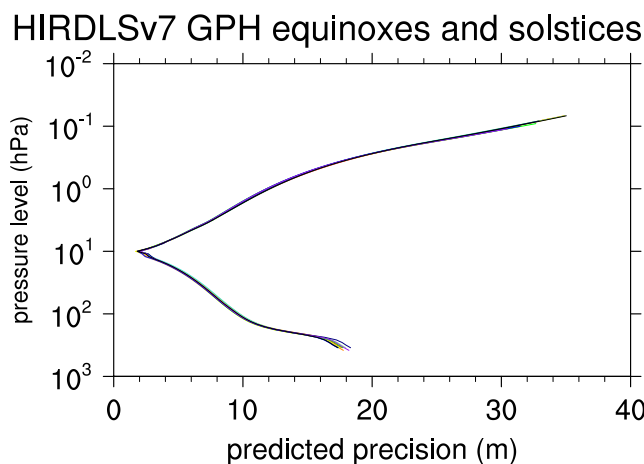

Figure 1. Predicted precision (m) of HIRDLS V7 GPH for 12 equinoxes and solstices 2005-2007.

the temperature at the tangent point is adjusted. For the a priori temperature the HIRDLS version 7 uses the GEOS v5.1.0 with an uncertainty of $\pm 2 \mathrm{~K}$ down to and including the HIRDLS measured cloud top - below which the retrieval merges smoothly into the GEOS-5 temperature.

When the retrieval is completed, the data are interpolated to pressure levels, with 24 levels per pressure decade, uniformly spaced in log pressure.

\subsection{HIRDLS GPH calculations}

We calculate HIRDLS geopotential height by calculating the thickness of the layers between HIRDLS pressure levels, and adding them up (or down) from a reference level. The layer thicknesses are computed via the standard $Z_{j}-Z_{i}=$ $\left(R_{d} / g_{0}\right)_{p j} \int^{p i} T \mathrm{~d} p / p$, where $Z_{j}-Z_{i}$ indicates GPH thickness between HIRDLS pressure levels, using as input the HIRDLS Level-2 temperatures. The reference level is a geometric altitude above the ellipsoid, obtained from the Science Data Processing (SDP) Toolkit software supplied by NASA (Noerdlinger, 1995). This combines spacecraft attitude data with instrument orientation and scan mirror position to provide an altitude associated with each radiance sample. We take the altitude closest to $30 \mathrm{~km}$ and identify it as the tangent height at nominal altitude (THNA). Thus the the HIRDLS GPHs are calculated utilizing only Aura satellite data. This paper is thus a test of this method.

The resulting HIRDLS geopotential heights have high vertical resolution, based on the high vertical resolution of HIRDLS temperature/pressure profiles. An averaging-kernel characterization of the retrieved temperatures gives a vertical resolution of $1-1.2 \mathrm{~km}$, and the retrieved products are output on a $\log$ pressure scale with 24 levels per decade of pressure. The predicted GPH precision is computed similarly, utilizing the predicted temperature precisions. As with the temperatures in the stratosphere, the geopotential height precision is independent of latitude and season, and varies from only slightly from the upper troposphere to about the stratopause,
HIRDLS V7 -- ERA-Interim (m/km)

(a) Average dGPH/dlat

(b) Average dGPH/dlon

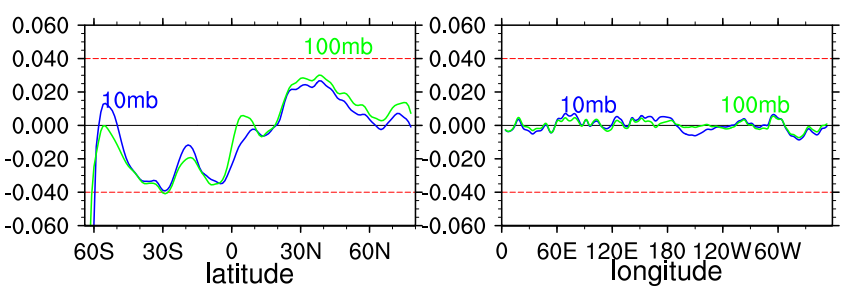

Figure 2. Derivatives of the differences of HIRDLS V7 GPH with ERA-Interim at 10 and $100 \mathrm{mb}$ for the entire HIRDLS mission, with respect to (a) latitude and (b) longitude.

above which it grows slightly, depending on latitude and season.

Figure 1 illustrates the predicted GPH precision estimated as follows: the chain rule applied to the standard GPH algorithm yields the predicted GPH precision per pressure level in terms of quantities such as the temperature precisions. Then the precision of GPH on each pressure level is computed by taking the square root of the sum of the squares that contribute to that level. In this figure, data used were from the equinoxes and solstices for years 2005-2007. The minimum uncertainty in the predicted GPH at approximately $10 \mathrm{hPa}$ corresponds to the location of the THNA. Notice the predicted uncertainty increases as we move away from the THNA because each successive layer increases the uncertainty.

The GPH is by definition the height above the geoid, a complicated surface of constant gravitational attraction over the Earth. The archived HIRDLS version 7 GPH data were based on the altitude of the THNA above a reference ellipsoid, a more regular and more easily used shape which was used to reference the height of the Aura satellite. To calculate the GPH values presented here, we modified the archived altitudes by subtracting the geoid heights above the ellipsoid (National Geospatial Intelligence Agency, 2008).

\section{Validation of geopotential heights}

An earlier version of HIRDLS Temperatures, version 3, was validated by Gille et al. (2008) via comparisons with data from high-resolution sondes, lidars, the Atmospheric Chemistry Experiment Fourier Transform Spectrometer (ACEFTS) and reanalyses. They conclude the HIRDLS temperatures are within $\pm 2 \mathrm{~K}$ of standard temperatures from the upper troposphere to the upper stratosphere, with the possible exception of the tropical tropopause region. HIRDLS temperatures show no indication of latitudinal variations of biases or temporal drifts. Moreover, the noise levels are consistent with predictions and low enough to make the data highly useful. Furthermore, the HIRDLS temperatures show an ability to resolve small vertical scales and capture atmospheric 

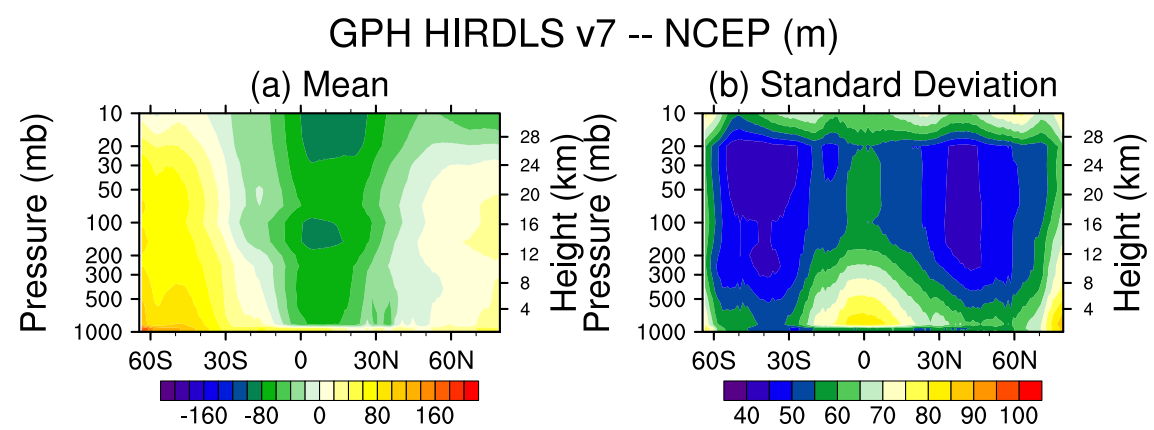

Figure 3. (a) Mean differences of zonal mean HIRDLS V7 GPH with respect to NCEP reanalyses for 2005-2007, (b) standard deviations of same differences, all in meters.

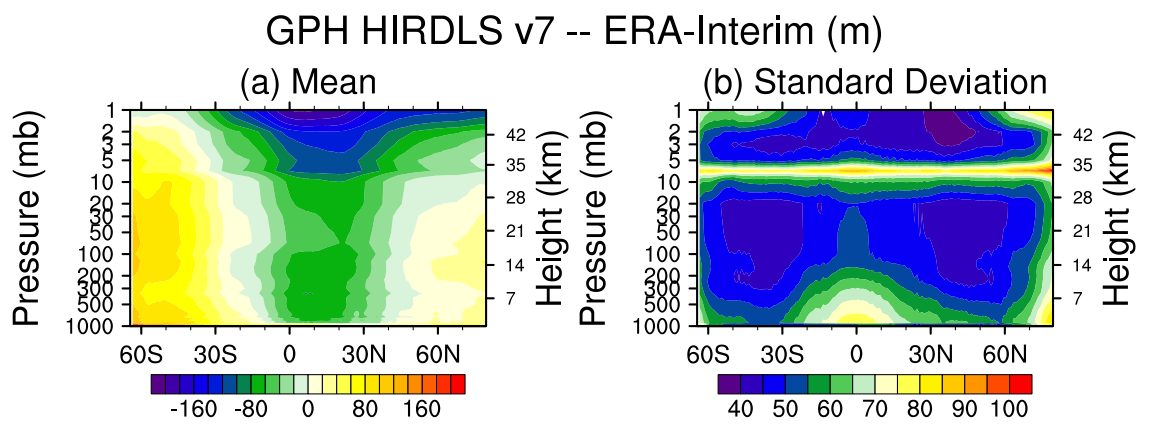

Figure 4. (a) Mean differences of zonal mean HIRDLS V7 GPH with respect to ERA-Interim for 2005-2007, (b) standard deviations of same differences, all in meters.

wave motions as discussed by Wright et al. (2011) for gravity waves and Alexander and Ortland (2010) for equatorial waves, for example.

As discussed in Gille et al. (2013), overall, the version 7 HIRDLS temperatures have a precision between $\leq 0.5 \mathrm{~K}$ (lower stratosphere) and $>3 \mathrm{~K}$ (mesopause) and are accurate to $\leq 1 \mathrm{~K}$ from the $300-400$ to $1 \mathrm{hPa}$, becoming cooler above that level.

The original HIRDLS measurements requirements (Gille et al., 1997) stated that the uncertainties in the horizontal geopotential height gradient should be no more than $20 \mathrm{~m} / 500 \mathrm{~km}$, or, stated another way, the derivatives of the differences of HIRDLS GPH with a standard data set must be smaller than $\pm 0.04 \mathrm{~m} \mathrm{~km}^{-1}$. This requirement enables one to compute geostrophic wind at $60^{\circ} \mathrm{N}$, for example, to better than $3 \mathrm{~m} \mathrm{~s}^{-1}$. Figure $2 \mathrm{a}$ and $\mathrm{b}$ show that the mean latitudinal and longitudinal derivatives of HIRDLS v7 GPH differenced with ERA-Interim GPH, for two sample pressure levels, averaged over the entire mission. While there are significant variations in Fig. 2a, both the latitudinal and longitudinal GPH derivatives meet the original measurement requirements because the derivatives are within the $\pm 0.04 \mathrm{~m} \mathrm{~km}^{-1}$ criteria.

In an attempt to determine the extent and magnitude of any bias, we compare HIRDLS v7 zonal mean GPH fields with the GPHs of other standard data sets. One such data set is the NCEP/NCAR 40-year Reanalysis Project, described in Kalnay et al. (1996). In Fig. 3a, we see the mean differences for 2005 through 2007, of HIRDLS V7 zonal mean GPH with NCEP zonal mean GPH. In general the pattern indicates HIRDLS V7 GPH is lower in the tropics and higher at higher latitudes. In Fig. $3 \mathrm{~b}$ we see the standard deviation of the differences with NCEP for 2005 through 2007. In general agreement of HIRDLS V7 GPH with NCEP GPH is good.

In Fig. 4a, we see the differences of HIRDLS V7 zonal mean GPH with ERA-Interim zonal mean for all ERAInterim-available vertical levels for 2005 through 2007. In Fig. $4 \mathrm{~b}$ we see the standard deviation of the differences with ERA-Interim for 2005 through 2007. The standard deviation does not vary much with latitude. The features in the standard deviations at $\sim 10 \mathrm{mb}$ are due to the HIRDLS THNA at that pressure level, from which we integrate. The ERA-Interim GPH does not have a similar reference level. Thus the standard deviations increase as we move away from $10 \mathrm{mb}$.

The mean differences of zonal mean HIRDLS V7 GPH with respect to GEOS-5 (not shown) and WACCM (shown in Supplement Fig. S1) are similar to the ERA-Interim comparisons. WACCM is a comprehensive numerical model spanning the range of altitude from the Earth's surface to the thermosphere and thus may be used for comparisons at high altitudes. For more information see Marsh et al. (2013) and references therein. Overall, from the zonal mean comparisons, 
(a) HIRDLSv7 2006d138 GPH (m)

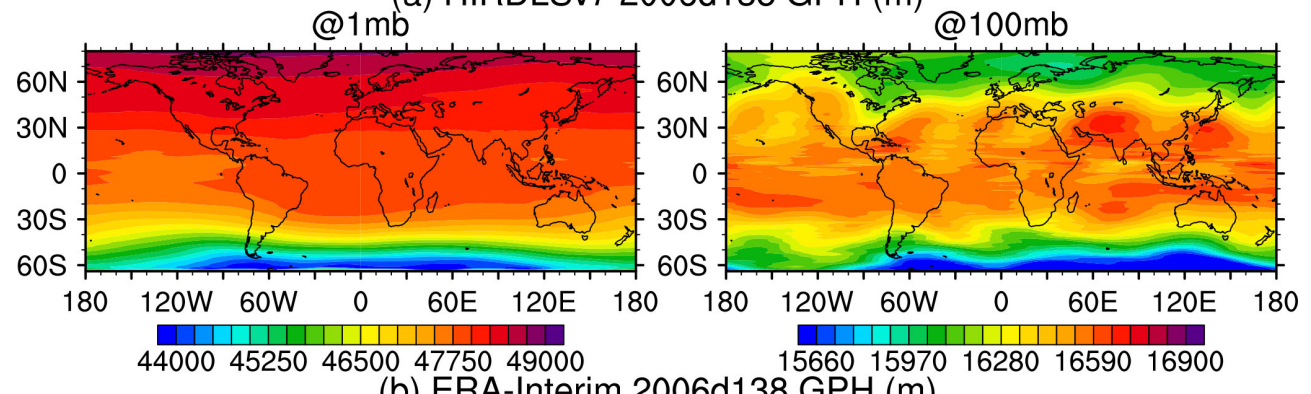

(b) ERA-Interim 2006d138 GPH (m)@100mb

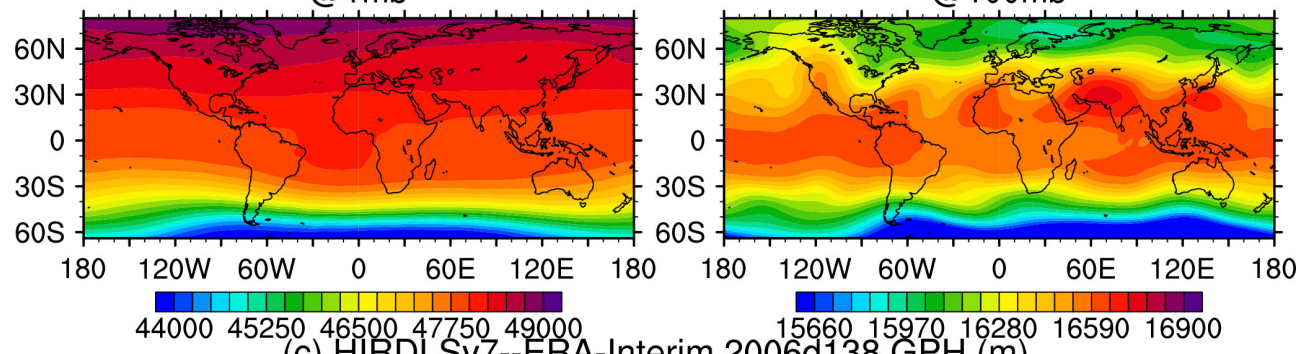

(c) HIRDLSv7--ERA-Interim 2006d138 GPH (m)

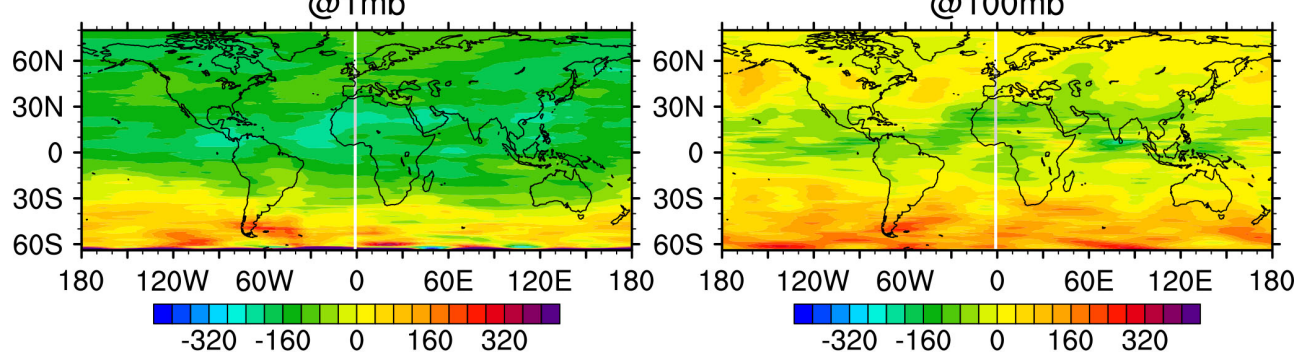

Figure 5. Mercator projection plots of (a) HIRDLS mapped GPHs for sample day $2006 \mathrm{~d} 138$ at 1 and $100 \mathrm{mb}$, (b) ERA-Interim mapped GPHs for the same sample day and levels, and (c) differences, all in meters.

the HIRDLS version 7 GPH appears to have a slight positive bias at high latitudes and a slight low bias in the tropics. It is not immediately apparent why this might be since the HIRDLS version 7 temperatures did not show a similar bias, but there may be systematic biases in the results provided by the Toolkit, or in our corrections to them

Because the Fourier coefficients are available every degree of latitude, they can be used to create $1^{\circ} \times 1^{\circ}$ latitudelongitude maps which can be compared with other standard global GPH data. Figure 5a shows the version 7 HIRDLS GPH Mercator map for sample day 18 May 2006, for two sample pressure levels, 1 and $100 \mathrm{mb}$. These levels are chosen because standard global GPH data sets also include these levels, and thus no vertical interpolation is required for comparisons. Figure 5b illustrates the ERA-Interim GPH Mercator map for the same situation. The latitudinal and longitudinal variations of the ERA-Interim data are very similar to those of the HIRDLS V7 data, except possibly at high latitudes. Both sets of data show the expected Southern Hemisphere high-latitude minima for this day at 1 and $100 \mathrm{mb}$ as well as the maxima at the tropics at $100 \mathrm{mb}$. Figure $5 \mathrm{c}$ (bottom row) illustrates the difference of HIRDLS V7 GPH and
ERA-Interim GPH. Note the maximum values in the difference plots are on the order of $\pm 100 \mathrm{~m}$ or less. Similar comparisons with GEOS-5, WACCM and NCEP Reanalysis data (not shown) are very similar. Overall, the Mercator map plots at $100 \mathrm{mb}$ may support a slight negative bias in HIRDLS version $7 \mathrm{GPH}$ in the tropics, with a slight positive bias at high latitudes, consistent with the zonal mean comparisons. Overall, the Mercator map plots at $1 \mathrm{mb}$ seem to indicate only a slight positive bias at high southern latitudes.

For a sample day in the winter season, we consider 21 December 2006. Figure 6 illustrates the HIRDLS V7 (top row) and ERA-Interim (middle row) GPH polar stereographic map for sample day 2006d355, for the same two pressure levels, 1 and $100 \mathrm{mb}$. The latitudinal and longitudinal variations of the ERA-Interim data are very similar to those of the HIRDLS V7 data. Both sets of data show the expected Northern Hemisphere minima for this day at 1 and $100 \mathrm{mb}$. This figure also illustrates the difference of HIRDLS V7 GPHs and ERA-Interim GPHs (bottom row). Note the maximum values in the difference plots are less than or on the order of $\pm 100 \mathrm{~m}$, and the HIRDLS data seem to show more fine structure. It is not known if this fine structure is physical. 
(a) HIRDLSv7 2006d355 GPH (m)
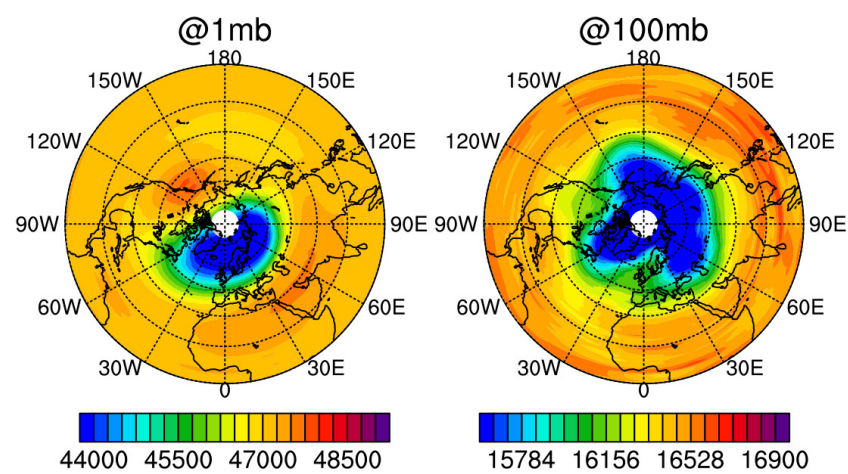

(b) ERA-Interim 2006d355 GPH (m)
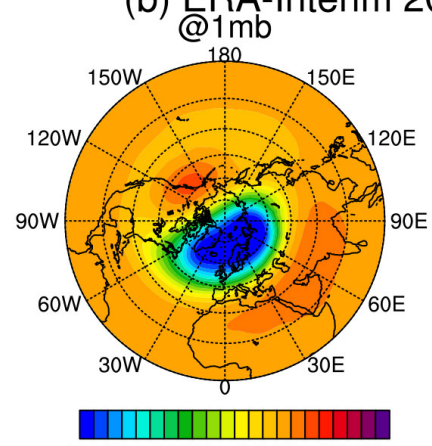

44000455004700048500

(c) HIRDLSv7--ERA-Interim $2006 \mathrm{~d} 355 \mathrm{GPH}(\mathrm{m})$

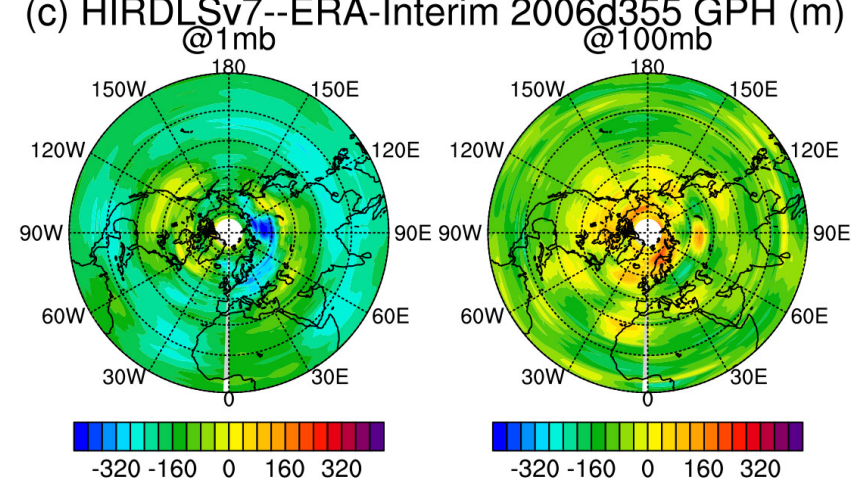

Figure 6. Polar stereographic plots of (a) HIRDLS V7, (b) ERAInterim mapped GPHs for sample day 2006d355 at levels 1 and $100 \mathrm{mb}$, and (c) differences, all in meters.

Notice that the gradients in the difference plots are relatively small.

Polar stereographic map GPH plots, and differences with HIRDLS V7, for similar levels and this sample day, 2006d355, with GEOS-5, WACCM and NCEP Reanalysis data (not shown) are similar. Generally, the polar stereographic plots at these levels show HIRDLS version 7 GPHs have a minor low bias in the Northern Hemisphere with respect to these data sets; that is, HIRDLS is cooler, with the exception of the highest latitudes.

To check for any possible systematic disagreements, we computed mean GPH differences with ERA-Interim GPH for 2005 through 2007, shown in Fig. 7. There appear to be biases with respect to ERA-Interim near the Equator, where mapped HIRDLS V7 GPHs are too low for all vertical levels. At high latitudes, HIRDLS V7 GPHs appear too high for all vertical levels. HIRDLS V7 GPH differences with NCEP Reanalysis GPH for 2005 through 2007 (not shown) show similar disagreement. Notice, however, all these disagreements are quantitatively on the order of $100 \mathrm{~m}$ or less of the geopotential height values. Again, the gradients of the differences appear to be small.

On the whole, the HIRDLS version 7 GPHs agree quite well with other data sets up to $1 \mathrm{hPa}$. This would appear to validate the HIRDLS method of computing GPH from temperatures and THNA. The HIRDLS version 7 GPHs appear to have a slight low bias in comparison with the specified data sets in the tropics and a slight high bias at high latitudes. Since the HIRDLS version 7 temperatures did not show this bias when compared to other data sets, possibly it comes from the THNA. This deserves further study.

\section{Comparison of geostrophic winds with other data sources}

As an additional test of the HIRDLS version 7 geopotential heights, one can compute the geostrophic winds from HIRDLS V7 GPH and compare the results to standard data sets. Of course, this will not produce usable winds in the tropics.

In Fig. 8a, we see the zonal winds derived from HIRDLS V7 for sample day 18 May 2006 and sample pressure levels 1 and $100 \mathrm{mb}$ (top row). In Fig. 8b, we see ERA-Interim for the same sample day and levels (middle row), and Fig. 8c shows their differences (bottom row). In Fig 8a and b, notice the large maxima at high southern latitudes and the band of minima along $30^{\circ} \mathrm{N}$ for the $1 \mathrm{mb}$ case. For the $100 \mathrm{mb}$ case, we see maxima at high latitudes, with some spots of minima in the tropics. Qualitatively, these plots agree very well. Regarding Fig. 8c, the differences show no systematic biases, and most differences are less than or on the order of $\pm 5 \mathrm{~m} \mathrm{~s}^{-1}$.

Mercator map GPH plots for this sample day and similar levels for NCEP, GEOS-5 (not shown) and WACCM zonal winds and their differences with HIRDLS V7-derived zonal geostrophic winds (shown in Supplement Fig. S2) are very similar. Overall, the differences of HIRDLS version 7 zonal wind with other zonal winds for this sample day and these levels show no systematic biases, and most differences are less than or on the order of $\pm 5 \mathrm{~m} \mathrm{~s}^{-1}$, consistent with the ERA-Interim case, above.

To double-check any possible temporal biases, we computed these zonal wind differences for 2005 through 2007, as shown in Fig. 9. The only significant (magnitudes greater than $5 \mathrm{~m} \mathrm{~s}^{-1}$ ) differences with other data sets are found near the Equator where the Coriolis factor introduces nonphysical results. 
(a) HIRDLSv7-ERA-Interim GPH (m) @1mb
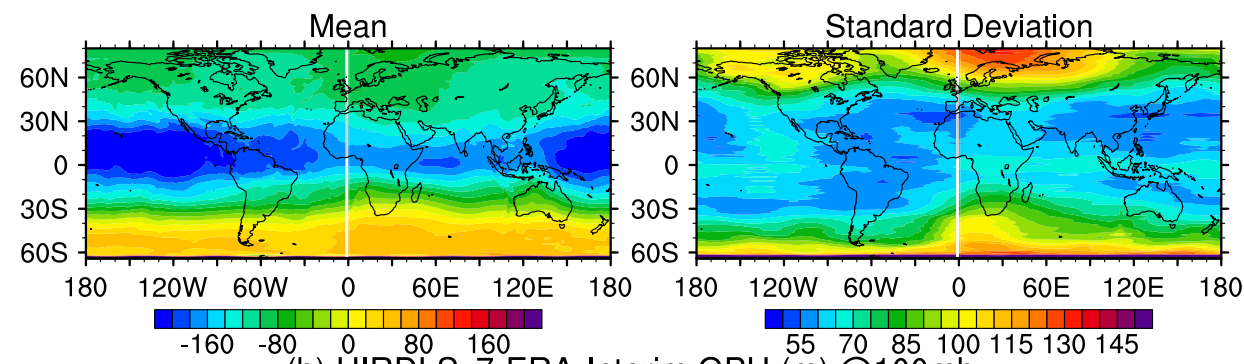

(b) HIRDLSv7-ERA-Interim GPH (m)@100mb

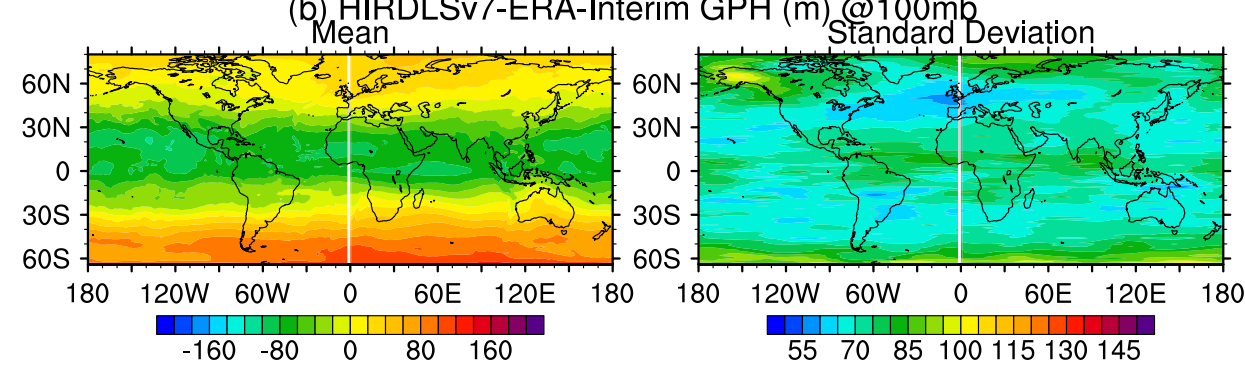

Figure 7. Mercator projection plots of mean HIRDLS V7 GPHs minus ERA-Interim GPHs and their standard deviation for 2005 through 2007, at (a) $1 \mathrm{mb}$, and (b) $100 \mathrm{mb}$, all in meters.

(a) HIRDLSv7 $2006 \mathrm{~d} 138 \mathrm{U}(\mathrm{m} / \mathrm{s})$
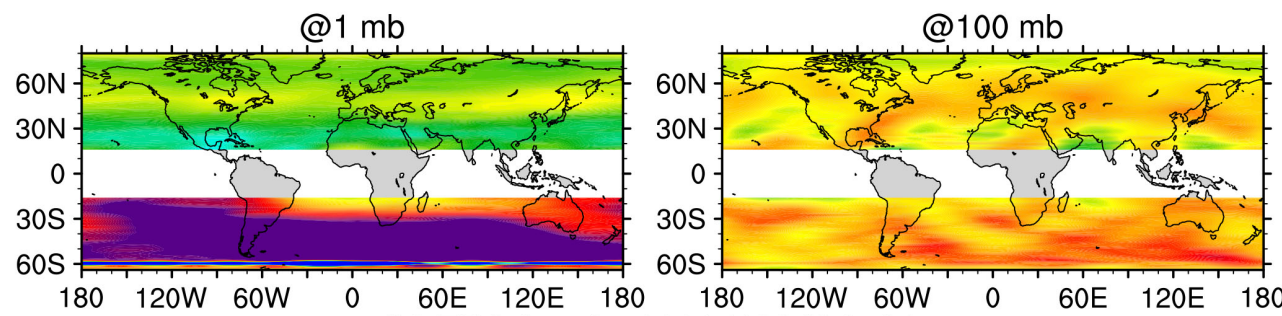

(b) ERA-Interim 2006d138 U (m/s) @100 mb

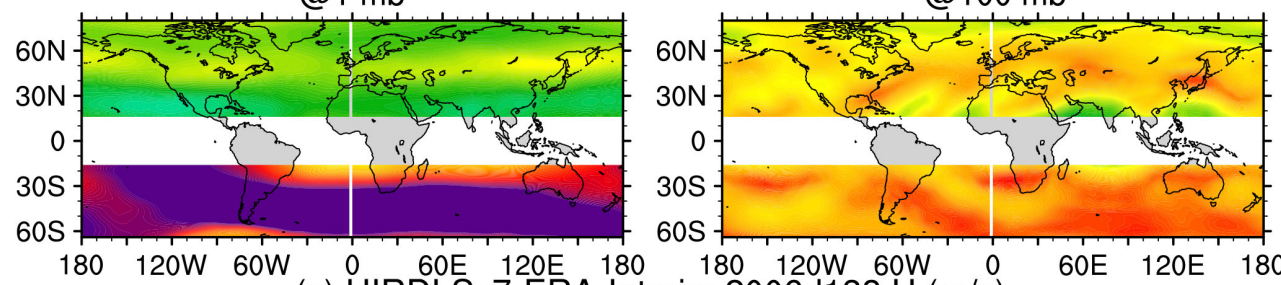

(c) HIRDLSv7-ERA-Interim 2006d138 U (m/s)

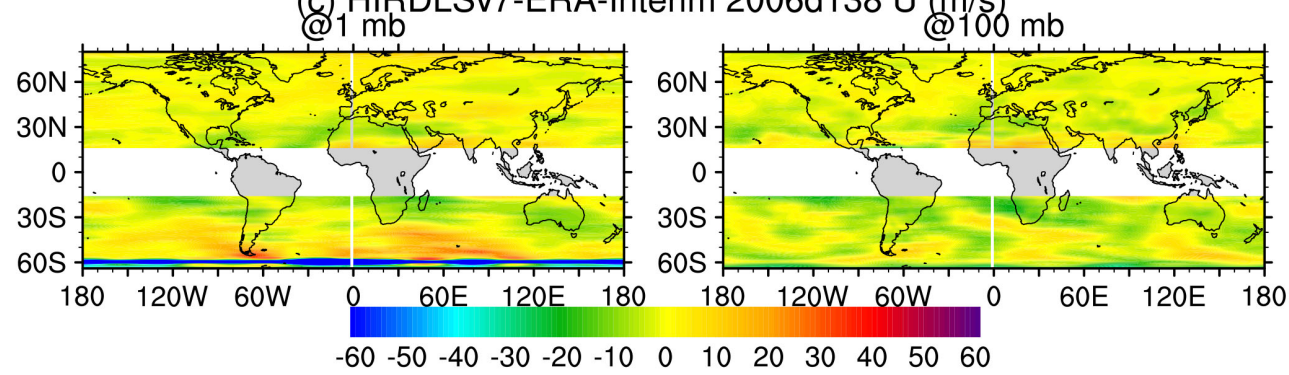

Figure 8. (a) HIRDLS V7 mapped zonal geostrophic winds for sample day 2006d138 at levels 1 and 100 mb, (b) ERA-Interim mapped zonal winds for the same sample day and levels, (c) HIRDLS V7 - ERA-Interim mapped zonal winds for same sample day and levels, all in meters per second. Values within 15 degrees of the Equator were discarded (because of the Coriolis factor). 
(a) HIRDLSv7--ERA-Interim U (m/s) @1mb
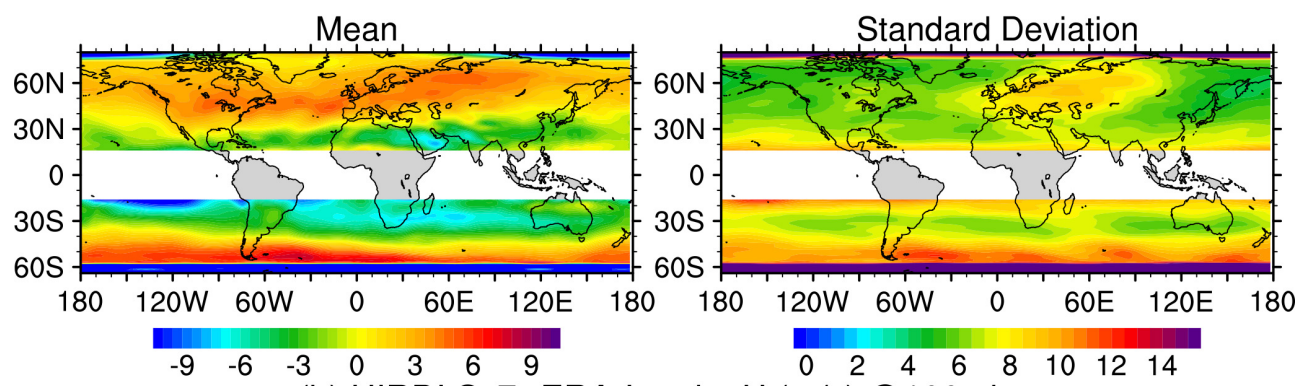

(b) HIRDLSv7--ERA-Interim U (m/s) @100mb
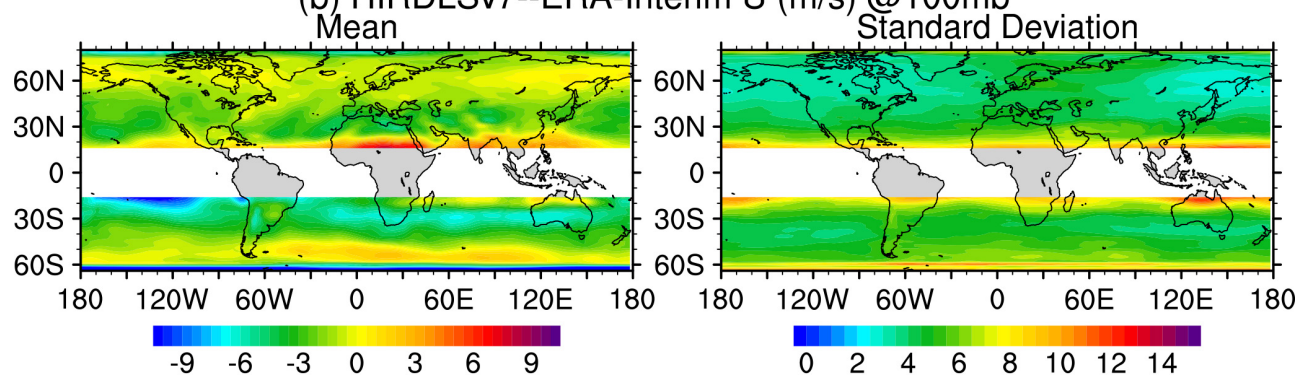

Figure 9. Mean HIRDLS V7 geostrophic zonal winds minus ERA-Interim mapped zonal winds and their standard deviation for 2005 through 2007, at (a) $1 \mathrm{mb}$, and (b) $100 \mathrm{mb}$, all in meters per second. Values within 15 degrees of the Equator were discarded.

(a) HIRDLSv7 2006d138 V (m/s)
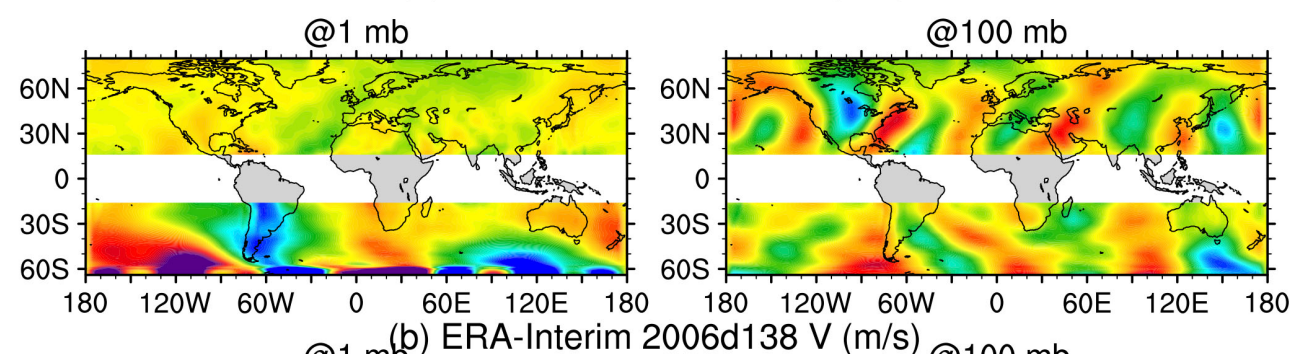

@1 mb) ERA-Interim 2006d138 V (m/s) @100 mb

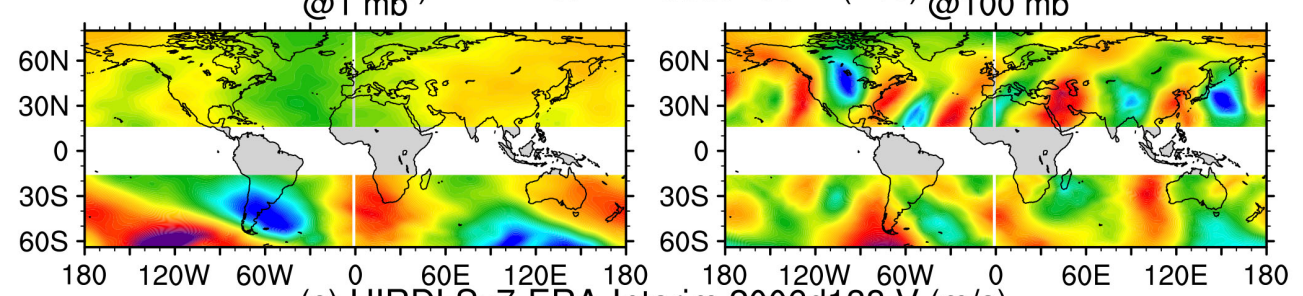

(c) HIRDLSv7-ERA-Interim 2006d138 V (m/s)

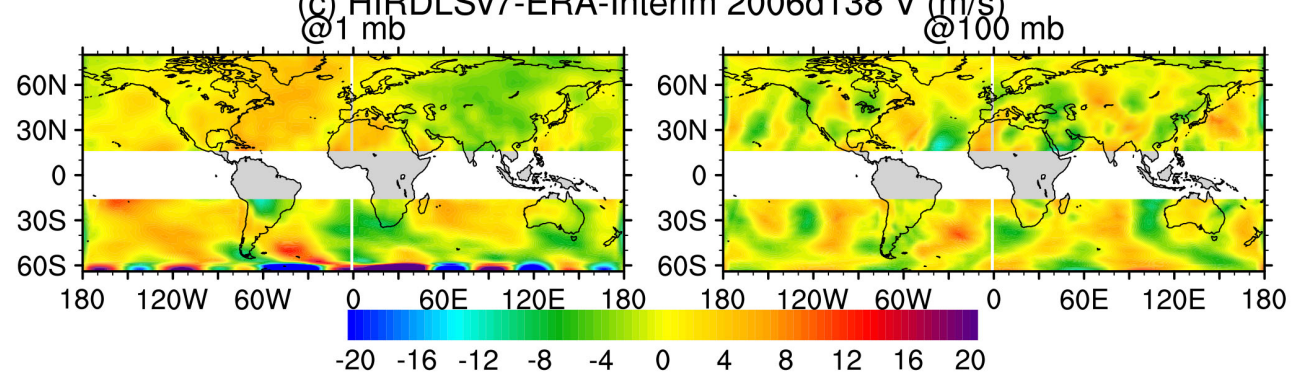

Figure 10. (a) HIRDLS mapped meridional geostrophic winds for sample day 2006d138 at 1 and 100 mb, (b) ERA-Interim mapped meridional winds for the same sample day and levels, and (c) their differences, all in meters per second. Values within 15 degrees of the Equator were discarded. 
(a) HIRDLSv7--ERA-Interim V (m/s) @1mb
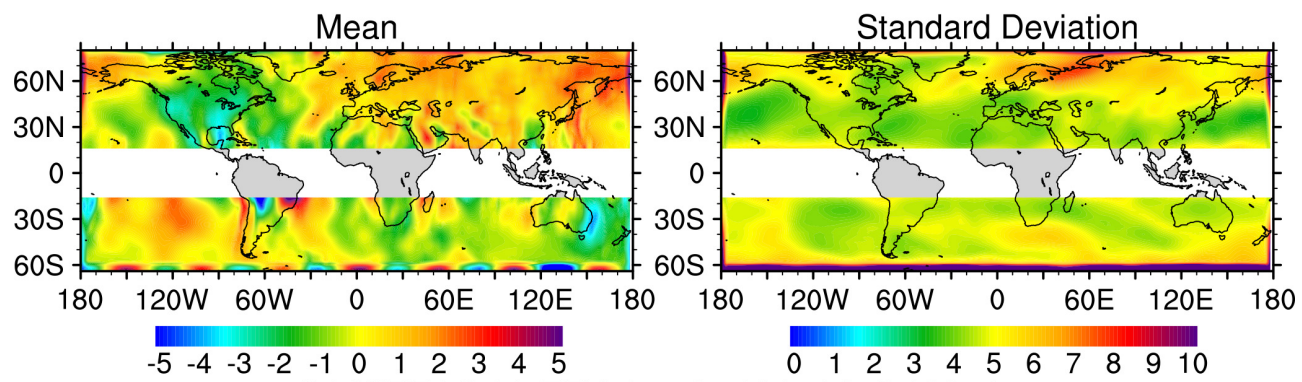

(b) HIRDLSv7--ERA-Interim V (m/s) @100mb
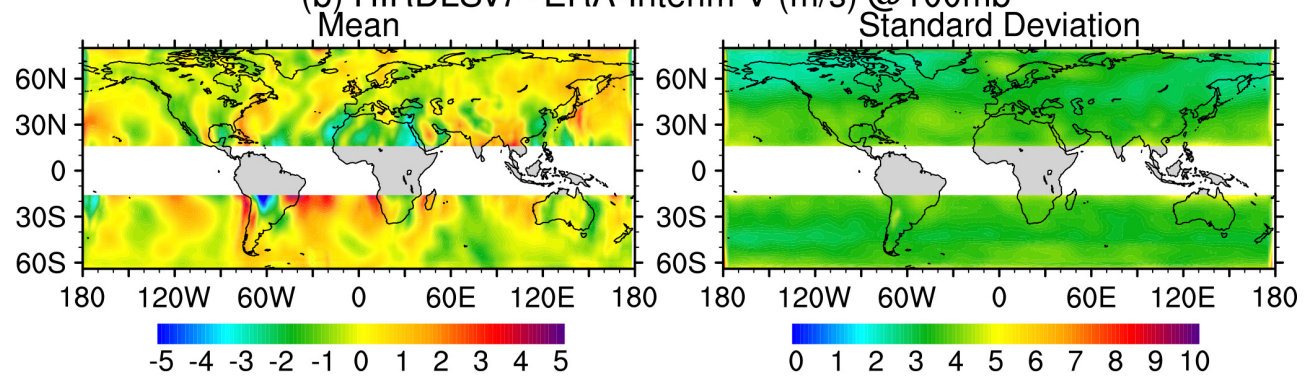

Figure 11. Mean HIRDLS V7 geostrophic meridional winds minus ERA-Interim meridional winds and their standard deviations for 2005 through 2007, at (a) $1 \mathrm{mb}$, and (b) $100 \mathrm{mb}$, all in meters per second. Values near the Equator were discarded.

In Fig. 10a we see the geostrophic meridional winds computed from HIRDLS V7 GPHs for sample day 18 May 2006 and sample pressure levels 1 and $100 \mathrm{mb}$ (top row). Figure 10b shows the meridional winds from ERA-Interim for sample day 18 May 2006 and sample pressure levels 1 and $100 \mathrm{mb}$ (middle row), with their differences in Fig. 10c (bottom row). The large maxima and minima coincide for the most part with the HIRDLS V7-derived meridional winds. Thus the large-scale pattern agrees.

Mercator map GPH plots for this sample day and similar levels for NCEP, GEOS-5 (not shown) and WACCM (shown in Supplemental Fig. 3) meridional winds and their differences with HIRDLS V7-derived meridional geostrophic winds are similar.

We examine the mean meridional wind differences for 2005 through 2007, and their standard deviations at 1 and $100 \mathrm{mb}$, as shown in Fig. 11a and b. Again, there are significant differences near the Equator where the Coriolis factor introduces nonphysical results. For the meridional winds, however, these differences appear to propagate to slightly higher latitudes, as shown in the difference plots.

Since, however, the HIRDLS version 7 GPH-derived geostrophic winds, particularly zonal winds, agree well with other winds away from the tropics, this would also seem to indicate the HIRDLS version 7 GPH products are scientifically useful.

\section{GPH and geostrophic winds in the mesosphere}

The HIRDLS temperatures are scientifically useful and valid up to $0.01 \mathrm{hPa}$ (Gille et al., 2013; France et al., 2012), so the GPH is expected to be useful up to similar altitudes. Sounding the Atmosphere by Broadband Emission Radiometry (SABER) and the Microwave Limb Sounder (MLS) are two satellite-borne instruments providing temperature observations that may be compared with HIRDLS in the mesosphere. HIRDLS global mean temperatures are observed to be lower than SABER's by $4 \mathrm{~K}$ below $70 \mathrm{~km}$ although differences in some latitude bands may be larger (Gille and Gray, 2013; C. Wright, personal communication, 2014), while France et al. (2012) find HIRDLS is low by $5-10 \mathrm{~K}$ in the mesosphere, and lower than MLS. However they note that

\section{HIRDLS accurately represents the daily large- scale geographic temperature anomaly pattern at $0.01 \mathrm{hPa}(\sim 80 \mathrm{~km})$, and the evolution of meso- spheric temperature anomalies before, during and after the January 2006 SSW (Sudden Stratospheric Warming).}

While models are subject to uncertainties at these levels, these results are consistent with the comparison with the WACCM global mean GPH shown in Supplement Fig. S1. Thus, we believe that while the HIRDLS GPHS will have a low bias in the mesosphere, the patterns will allow useful winds to be calculated, up to $80 \mathrm{~km}$. 


\section{Conclusions}

The version 7 HIRDLS geopotential heights are considered scientifically useful at pressures from 1000 to $0.01 \mathrm{hPa}$. Data comparisons indicate the HIRDLS GPHs have an altitudedependent precision ranging from 2 to $30 \mathrm{~m}$ and an accuracy of $\pm 100 \mathrm{~m}$ up to $1 \mathrm{hPa}$, and the HIRDLS GPHs may have a slight low bias in the tropics and a slight high bias at high latitudes, of less than $100 \mathrm{~m}$. Therefore, HIRDLS version 7 GPHs have good precision and accuracy. This satellite data set should be quite useful for scientific studies.

\section{The Supplement related to this article is available online at doi:10.5194/amt-7-2775-2014-supplement.}

Acknowledgements. The authors would like to thank the entire HIRDLS team for excellent work in a challenging situation. We'd also like to thank L. Henderson for help with this paper.

The authors would like to thank D. E. Kinnison of NCAR's Atmospheric Chemistry Division for supplying us with the SDWACCM data and for helpful discussions.

The authors would like to thank C. Wright of the Centre for Space, Atmospheric and Ocean Science at the University of Bath, Bath, UK, for helpful discussions of

comparisons of HIRDLS data with Sounding of the Atmosphere using Broadband Emission Radiometry (SABER) data at high altitudes.

The graphics here were made with The NCAR Command Language (version 6.1.2) [Software] (2013). Boulder, Colorado: UCAR/NCAR/CISL/VETS. http://dx.doi.org/10.5065/ D6WD3XH5.

The European Centre for Medium-range Weather Forecasting (ECMWF) ERA-Interim assimilated data for this study are from the Research Data Archive (RDA) which is maintained by the Computational and Information Systems Laboratory (CISL) at the National Center for Atmospheric Research (NCAR). NCAR is sponsored by the National Science Foundation (NSF). The original data are available from the RDA (http://dss.ucar.edu) in data set number ds627.0.)

The National Center for Atmospheric Research is sponsored by the National Science Foundation. Any opinions, findings and conclusions or recommendations expressed in the publication are those of the author(s) and do not necessarily reflect the views of the National Science Foundation.

Edited by: M. Nicolls

\section{References}

Alexander, M. J. and Ortland, D. A.: Equatorial waves in High Resolution Dynamics Limb Sounder (HIRDLS) data, J. Geophys. Res. Atmos., 115, D24111, doi:10.1029/2010JD014782, 2010.

Dee, D. P., Uppala, S. M., Simmons, A. J., Berrisford, P., Poli, P., Kobayashi, S., Andrae, U., Balmaseda, M. A., Balsamo, G., Bauer, P., Bechtold, P., Beljaars, A. C. M., van de Berg, L., Bidlot, J., Bormann, N., Delsol, C., Dragani, R., Fuentes, M., Geer, A. J., Haimberger, L., Healy, S. B., Hersbach, H., Holm, E. V.,
Isaksen, L., Kallberg, P., Kohler, M., Matricardi, M., McNally, A. P., Monge-Sanz, B. M., Morcrette, J. J., Park, B. K., Peubey, C., de Rosnay, P., Tavolato, C., Thepaut, J. N., and Vitart, F.: The ERA-Interim reanalysis: configuration and performance of the data assimilation system, Q. J. Roy. Meteorol. Soc., 137, 553597, doi:10.1002/qj.828, 2011.

France, J. A., Harvey, V. L., Alexander, J. J., Randall, C. E., and Gille, J. C.: High resolution Dynamics Limb Sounder observations of the gravity wave-driven elevated stratopause in 2006, J. Geophys. Res., 117, D20108, doi:10.1029/2012JD017956, 2012.

Gille, J. C. and House, F. B.: On the inversion of limb radiance measurements, I. Temperature and thickness, J. Atmos. Sci., 28, 1427-1442, 1971.

Gille, J. C., Barnett, J. J., and Boville, B.: The Science Requirements Document, SC-HIR-012C, Oxford University and University of Colorado, Boulder, available at: http://www.eos.ucar.edu/ hirdls (last access: 31 December 2004), 1997.

Gille, J., Barnett, J., Arter, P., Barker, M., Bernath, P., Boone, C., Cavanaugh, C., Chow, J., Coffey, M., Craft, J., Craig, C., Dials, M., Dean, V., Eden, T., Edwards, D. P., Francis, G., Halvorson, C., Harvey, L., Hepplewhite, C., Khosravi, R., Kinnison, D., Krinsky, C., Lambert, A., Lee, H., Lyjak, L., Loh, J., Mankin, W., Massie, S., McInerney, J., Moorhouse, J., Nardi, B., Packman, D., Randall, C., Reburn, J., Rudolf, W., Schwartz, M., Serafin, J., Stone, K., Torpy, B., Walker, K., Waterfall, A., Watkins, R., Whitney, J., Woodard, D., and Young, G.: High Resolution Dynamics Limb Sounder: Experiment overview, recovery, and validation of initial temperature data, J. Geophys. Res., 113, D16S43, doi:10.1029/2007JD008824, 2008.

Gille, J., Gray, L., Cavanaugh, C., Coffey, M., Dean, V., Halvorson, C., Karol, S., Khosravi, R., Kinnison, D., Massie, S., Nardi, B., Belmonte-Rivas, M., Smith, L., Torpy, B., Waterfall, A., and Wright, C.: High Resolution Dynamics Limb Sounder Earth Observing System (EOS) Data Description and Quality Version 7, 2013.

Kalnay, E., Kanamitsu, M., Kistler, R., Collins, W., Deaven, D., Gandin, L., Iredell, M., Saha, S., White, G., Woollen, J., Zhu, Y., Chelliah, M., Ebisuzaki, W., Higgins, W., Janowiak, J., Mo, K. C., Ropelewski, C., Wang, J., Leetmaa, A., Reynolds, R., Jenne, R., and Joseph, D.: The NCEP/NCAR 40-year reanalysis project, Bull. Am. Meteorol. Soc., 77, 437-471, doi:10.1175/15200477(1996)077<0437:TNYRP>2.0.CO;2, 1996.

Khosravi, R., Lambert, A., Lee, H., Gille, J., Barnett, J., Francis, G., Edwards, D., Halvorson, C., Massie, S., Craig, C., Krinsky, C., McInerney, J., Stone, K., Eden, T., Nardi, B., Hepplewhite, C., Mankin, W., and Coffey, M.: Overview and characterization of retrievals of Temperature and atmospheric constituents from HIRDLS measurements, J. Geophys. Res., 114, D20304, doi:10.1029/2009JD011937, 2009a.

Khosravi, R., Lambert, A., Lee, H., Gille, J., Barnett, J., Francis, G., Edwards, D., Halvorson, C., Massie, S., Craig, C., Krinsky, C., McInerney, J., Stone, K., Eden, T., Nardi, B., Hepplewhite, C., Mankin, W., and Coffey, M.: Correction to "Overview and characterization of retrievals of temperature, pressure, and atmospheric constituents from the HIgh Resolution Dynamics Limb Sounder (HIRDLS) measurements", J. Geophys. Res., 114, D23399, doi:10.1029/2009JD013507, 2009b.

Kohri, W. J.: LRIR Observations of the Structure and Propagation of the Stationary Planetary Waves in the Northern Hemisphere 
during December, 1975, Cooperative Thesis No. 63, Drexel University and National Center for Atmospheric Research, 1981.

Marsh, D. R., Mills, M. J., Kinnison, D. E., Lamarque, J.-F., Calvo, N., and Polvani, L. M.: Climate change from 1850 to 2005 simulated in CESM1 (WACCM), 73727391, J. Climate., 26, 73727391, doi:10.1175/JCLI-D-12-00558.1, 2013.

National Geospatial Intelligence Agency: Earth Gravitational Model, available at: http://earth-info.nga.mil/GandG/ wgs84/gravitymod/egm2008/egm08_wgs84.html (last access: 30 June 2014), 2008.

Noerdlinger, P. D.: Theoretical Basis of the SDP Toolkit Geolocation Package for the ECS Project, 445-TP-002-002, see also NASA SDP Toolkit/HDF-EOS EOSDIS Core System Project, available at: http://newsroom.gsfc.nasa.gov/sdptoolkit/ toolkit.html (last access: 31 December 2002), 1995.
Poli, P., Healy, S. B., and Dee, D. P.: Assimilation of Global Positioning System radio occultation data in the ECMWF ERAInterim reanalysis, Q. J. Roy. Meteorol. Soc., 136, 1972-1990, doi:10.1002/qj.722, 2010.

Remsberg, E. E., Haggard, K. V., and Russell III, J. M.: Estimation of Synoptic Fields of Middle Atmosphere Parameters from Nimbus-7 LIMS Profiles Data, J. Atmos. Ocean. Technol., 7 , 689-705, 1990.

Rodgers, C. D.: Inverse Methods for Atmospheric Sounding, Theory and Practice, World Sci., Hackensack, NJ, 2000.

Wright, C. J., Rivas, M. B., and Gille, J. C.: Intercomparisons of HIRDLS, COSMIC and SABER for the detection of stratospheric gravity waves, Atmos. Meas. Tech., 4, 1581-1591, doi:10.5194/amt-4-1581-2011, 2011. 